\title{
EDITORIAL
}

\section{Italian democracy the day after the local elections}

The day before we began writing this editorial, the results of the second round of the local elections were announced. Although they involved only around one quarter of the Italian electorate and were of the second-order variety, their outcome was widely framed in the media as a significant defeat for Matteo Renzi and therefore to a significant extent were so: in politics, perhaps more than in any other sphere, a situation defined as real is real in its consequences. The loss of Rome, where support for Renzi's party was halved, was not unexpected given the allegations of improbity that had plagued former mayor, Ignazio Marino, and given the corruption scandal, 'mafia capitale', that had involved other members of the council; and clearly, outcomes generally reflected the operation of local factors: yes, the Five-star Movement (M5s) did spectacularly well with its $67 \%$ in Rome for example - but in most of the 126 other municipalities where run-off ballots were held, its support remained below $20 \%$ and in a small number of cases it struggled to reach double figures; yes, the Democratic Party (PD) performed lamentably in places like Rome and Naples (where its mayoral candidate failed even to make the run-off) - but in Milan the centre left was able to turn a slender first-round advantage of less than $1 \%$ over the centre right into a decisive second-round advantage of almost $4 \%$. And yet the elections reflected the operation of national factors too: voters did seem to use them as an opportunity to reward or punish national-level public office holders - as the Turin results suggest; for here was a popular incumbent mayor, the PD's Piero Fassino, widely perceived to have governed, if not spectacularly, at least reasonably well. And yet he, like his colleague, Roberto Giachetti, in Rome was roundly defeated by the $\mathrm{M} 5 \mathrm{~s}$ - with the additional humiliation that he was beaten by an M5s that after the first round of voting had trailed him by ten percentage points.

So it is not surprising that the results have been widely interpreted as a significant defeat for Renzi; for what the M5s victories in such large and therefore high-profile municipalities as Rome and Turin do is to add to the impression that voters have been driven by the usual anti-political sentiments and consequent feelings of anger against the 'caste' of professional politicians - feelings which, with supreme irony, Renzi's own conduct is likely to have stoked: having built his political fortunes on the back of popular demands for decisive action by someone capable of challenging established elites in the interests of political renewal, he has taken full advantage of the mediatisation and the personalisation of politics to dominate his party and to hold centre stage - with the result that, with the end of his 'honeymoon' as premier, he has to an extent come to personify the hated elite citizens believed he had vowed to destroy!

And the results have been interpreted as a significant set-back for Renzi for another reason; for what the M5s victories have also done is to make clear that the Movement poses a potential threat to the PD in particular and to the mainstream parties in general that is far greater than one would assume just by looking at its voting percentages, which all in all were quite modest. The threat arises from the nature of the electoral system and the Movement's nature as a party. Among the municipalities of over 15,000 inhabitants where run-offs were required because no candidate achieved $50 \%$ at the first round of voting on 5 June, the M5s achieved a second-ballot place in only twenty cases. However, it was able to win all but one of these contests because, as an anti-political catch-all party it was able to mobilise not only its own habitual supporters, but also the habitual supporters of almost all the parties opposed to the candidate, whether of the centre left or the centre right, it found itself up against. In other words, in a straight fight of the kind characterising a run-off ballot, the M5s becomes extremely formidable - so it is of not insignificant moment that the electoral law which Renzi has managed to introduce for the Chamber of Deputies is also based on the principle of run-off ballots which, in another irony, had originally been conceived as a means of excluding the 
M5s from power. It means, given the local-election outcomes, that he is now likely to find it even harder than he has hitherto to keep the lid on at least that part of the turbulence in his party that is driven by opposition to his law. And here we encounter the possible development of that old vicious circle whereby declining authority and capacity to govern produces declining popularity and declining authority and so on.

And if that happens, then this poses significant problems for Renzi's capacity to win, in the autumn, the constitutional referendum on which he has staked his political career; for he has said that he will 'go home' if the referendum is lost thus framing the vote as a plebiscite on a premiership that has just been weakened by the local elections. Indeed he himself made a major contribution to such weakening during the campaign when he insisted that the contests were purely local matters without implications for his national-level authority which would, rather, be tested in the autumn. By loudly asserting that the elections were not a vote about him, that is precisely what, to a large extent they became.

If, then, the autumn referendum is lost, the almost certain outcome is likely to be a rumbling on in Italy of the crisis of democracy that is affecting Europe generally - either because defeat for the constitutional reforms at stake in the referendum will mean the actual loss of a significant opportunity for democratic renewal (though that is debatable) or else its perceived loss, or both. And that will provide significant opportunities for the M5s. Whether and to what extent it would be able to make good use of such opportunities can only be a matter of speculation. Certainly there is plenty of room for doubt. Governing would force it to make difficult and potentially unpopular choices it does not have to make as a protest movement. As Renzi has discovered, it is difficult to overhaul institutions from the inside and avoid raising the suspicion that one has gone native. Bossi and Berlusconi before him did so. Long before them, Pareto had pointed out that regime change is largely a matter of the circulation of elites. 'Nothing in this world', Benjamin Franklin wrote, 'can be said to be certain, except death and taxes'. Should one add to this list a continuation, for at least the foreseeable future, of the problems of Italian democracy? 